\title{
Factors influencing medical students' choice of emergency medicine as a career specialty-a descriptive study of Saudi medical students
}

\author{
Hadeel Alkhaneen ${ }^{1}$, Faisal Alhusain ${ }^{1} \mathbb{B}$, Khalid Alshehri ${ }^{1}$ and Nawfal Al Jerian² ${ }^{*}$
}

\begin{abstract}
Background: Choosing a medical specialty is a poorly understood process. Although studies conducted around the world have attempted to identify the factors that affect medical students' choice of specialty, data is scarce on the factors that influence the choice of specialty of Saudi Arabian medical students, in particular those planning a career in emergency medicine (EM). In this study, we investigated whether Saudi medical students choosing EM are influenced by different factors to those choosing other specialties.

Methods: A cross-sectional survey was conducted at King Saud bin Abdulaziz University for Health Sciences (KSAUHS), Riyadh, Saudi Arabia. The questionnaire distributed among all undergraduate and postgraduate medical students of both sexes in the second and third phases ( $57 \%$ were males and $43 \%$ were females).

Results: A total of 436 students answered the questionnaire, a response rate of 53.4\%. EM group was most influenced by hospital orientation and lifestyle and least influenced by social orientation and prestige provided by their specialty. Unlike controllable lifestyle (CL) group and primary care (PC) group, EM reported lesser influence of social orientation on their career choice. When compared with students primarily interested in the surgical subspecialties (SS), EM group were less likely to report prestige as an important influence. Moreover, students interested in SS reported a leaser influence of medical lifestyle in comparison to EM group. When compared with $\mathrm{CL}$ group, EM group reported more interest in medical lifestyle.

Conclusions: We found that students primarily interested in EM had different values and career expectations to other specialty groups. The trends in specialty choice should be appraised to meet future needs.
\end{abstract}

Keywords: Emergency medicine, Medical education, Future career, Saudi Arabia

\section{Background}

Choosing a medical specialty is a complex, poorly understood process with implications for both the student and physician workforces. It is an important predictor of the future supply of doctors in different specialties. Identifying the factors underlying the choice of a specialty may improve our understanding of students' preferences for particular specialties and help careers advisors to provide better guidance for medical students [1,2]. Factors that

\footnotetext{
* Correspondence: nawfalaljerian@gmail.com

${ }^{2}$ Department of Emergency Medicine, Ministry of National guard health

affairs, P.O Box 86871, Riyadh 11632, Saudi Arabia

Full list of author information is available at the end of the article
}

influence the choice of a medical specialty include the following: specialty-related lifestyle, exposure to a role model, income, length of residency training, varied scope of practice, and patient population. Recently, "controllable lifestyle" (CL) became a significant factor when choosing a specialty [2]. A study undertaken by Dorsey et al. [2] found that $55 \%$ of the variation in the specialty preferences of United States (US) medical graduates between 1996 and 2002 could be explained by their CL [2]. Specialties that can provide a CL, such as dermatology, anesthesiology, and emergency medicine (EM), are attracting increasing numbers of medical students every year $[1,3]$. 
Studies conducted around the world, including in the USA [4], Canada [1, 5], Brazil [6], and Japan [7], have attempted to identify the factors that affect medical students' choice of specialty. However, the process by which medical students in the Middle East choose their future career requires further investigation. A study undertaken at Kuwait University showed that observing good treatment outcomes followed by working in a demanding specialty are the most influential factors when choosing a specialty according to Kuwaiti medical students [8]. Factors associated with choosing a career in primary care (PC) have been well-studied in an attempt to address the decreasing number of students interested in this field $[1,9]$. However, few studies have endeavored to determine the factors associated with choosing a career in EM [1, 7]. One study involving Canadian medical students primarily interested in a career in EM between 2001 and 2004 found that medical lifestyle, hospital orientation, and varied scope of practice play a major role in their career choice [1].

EM is considered a new medical specialty and is expanding at a phenomenal pace worldwide. EM training in Saudi Arabia was established in the year 2000 by newly graduated physicians who had completed their EM training in the USA. The first batch of Saudi Arabian students to graduate from the Saudi Board of Emergency Medicine (SBEM) in 2004 consisted of four physicians. The number of available residency positions in the specialty has increased over time. In 2012, 80 qualified EM physicians graduated from the SBEM [10]. However, data is scarce on the factors that affect the choice of specialty of Saudi Arabian medical students, in particular those planning a career in EM. Therefore, in this study, we investigated whether Saudi Arabian medical students choosing EM are subjected to different influential factors to students choosing other specialties.

\section{Methods}

\section{Study design}

This cross-sectional study was conducted at the King Saud bin Abdulaziz University for Health Sciences (KSAU-HS), Riyadh, Saudi Arabia, from March to May of the 2016/2017 academic year. The aim of this study was to determine whether students who are interested in a career in EM have a different profile of influential factors to students choosing other specialties.

Specialties were classified into four groups: EM, PC, CL, and surgical specialty (SS). CL specialties were determined based on a study by Schwartz et al. [3], which examined the influence of CL on specialty choice. The CL group consisted of anesthesiology, neurology, ophthalmology, radiology, otolaryngology, pathology, dermatology, and psychiatry. The PC group included internal medicine, family medicine, pediatrics, and obstetrics/ gynecology. The SS group included general surgery, plastic surgery, urology, and orthopedic surgery. Although Schwartz et al. [3] considered EM to be a CL specialty,
EM was excluded from the CL Group because it was our group of interest.

\section{Study setting and population}

This study was conducted in the College of Medicine at the KSAU-HS. It is the first public university in the Kingdom of Saudi Arabia and Middle East region specializing in health sciences. Its headquarters is in the main campus in Riyadh, Saudi Arabia. It has two other campuses in Jeddah and Al-Ahsa. The KSAU-HS provides both undergraduate and postgraduate programs: a 6-year program for undergraduates and a 5-year program for postgraduates. The college uses a problem-based learning medical education curriculum that is split into three phases: pre-med, pre-clinical, and clinical. Each phase is 2 years long. Students are termed medical students after completing the 2-year pre-med phase.

\section{Questionnaire}

We distributed a 41-item self-administered and validated questionnaire to all undergraduate and postgraduate medical students of both sexes in the second and third phases, i.e., first- to fourth-year students, and excluded first-phase, pre-med students. The questionnaire was adapted from a study by Scott et al. [1] and used with permission. The questionnaire was carefully revised so that it fulfilled the objectives of the study. The survey gave students a choice between eight major career options: EM, family medicine, internal medicine, obstetrics/gynecology, pediatrics, psychiatry, surgery, and "other" (a write-in choice). They were asked to indicate with a "yes" or "no" which they considered a possible career and to rank their top three career choices. The students then evaluated the extent to which 27 variables influenced their first choice, using a 5-point Likert scale ranging from 1 (no influence) to 5 (major influence). Demographic data were also collected.

\section{Data management and analyses}

Demographic characteristics, including sex, academic year, and specialty preference, were summarized and reported in terms of frequencies and percentages. Factors that influenced students' career choices were categorized into six new descriptive groups (medical lifestyle, social orientation, prestige, hospital orientation, role model, and varied scope of practice) according to the ability of items to fit in these categories. Table 1 shows the categorization. Social orientation of medicine includes the desire to contribute to the community, patient population and the ability to have enough free time to spend with family and friends. Hospital orientation focuses more on the practice inside the hospital and what kind of care are going to be provided (urgent vs non-urgent). Prestige mainly means income and status among medical profession. Medical lifestyle was defined by Schwartz et al. [3] as "control of 
Table 1 Factors and underlying influences that affect the career choices of medical students

\begin{tabular}{ll}
\hline Medical lifestyle & Acceptable on-call schedule \\
& Research interest \\
& Acceptable hours of practice \\
& Flexibility inside of medicine \\
& Flexibility outside of medicine \\
& Keep options open \\
& Short postgraduate training \\
& Less intense residency program \\
& Patient population is interesting \\
& Focus on patients in community \\
& Long-term patient relationship \\
& Social commitment \\
Social orientation & Health promotion is important \\
& Able to spend appropriate time \\
& with my family \\
& High income potential \\
& Status among colleagues \\
& Stable/secure future \\
Focus on in-hospital care & Focus on urgent care \\
& Focus on non-urgent care \\
Intervention results immediate & Don't like uncertainty \\
& Prefer medical to social problems \\
Hospital orientation & Frestige
\end{tabular}

Role model Good match to career

Emulate physician

Meaningful past experience

Experiences in health fields during medical school

Experiences with role models during medical school

Varied scope of practice Wide variety of patient problems

Narrower variety of patient problems

For each factor, the average of the Likert scores for items in that factor was computed. Analysis of variance was then used to compare factor scores according to career choice

work hours". Factors related to the impact of role model and variety of practice was also considered. The mean \pm standard deviation of the Likert scale data for each unique factor and for the new generated categories among career interest groups were calculated. Analysis of variance with a Bonferroni post hoc test was used to compare the influential factors among the different career interest groups. A $P$ value $\leq 0.05$ was considered to indicate statistical significance. All computations were performed using SPSS version 23 (IBM Corp., Armonk, NY, USA).

\section{Results}

A total of 436 students answered the questionnaire, a response rate of $53.4 \%$. Of the respondents, $57 \%$ were males and $43 \%$ were females. PC specialties were the most commonly cited first-choice of our students, followed by SS specialties. Only $7 \%$ of the students named EM as their first-choice specialty. Twenty-eight students expressed no specific preference regarding their future career specialty and were excluded from the study. Table 2 shows the baseline characteristics and specialty groups of the participants.

Hospital orientation, social orientation, and medical lifestyle factors were the most frequently cited factors influencing the process of choosing a medical career (with high influence, $P<0.001$ ). Hospital orientation factors were the most commonly cited factors in the EM and SS groups. Prestige was the least commonly reported factor in the EM group and one of the top three influential factors in the SS group. Social orientation factors were the most commonly cited factors in the PC and CL groups. The effect of a role model was the least commonly reported factor in the PC and CL groups. Interestingly, varied scope of practice had the least impact on the EM group compared with the other three groups. Table 3 shows a comparison of factors influencing the career interests of medical students.

Students choosing EM reported that its focus on urgent care and high-income potential were the most important influences on their career choice. CL specialties were chosen for their acceptable hours of practice and mostly acceptable on-call schedule. For those who chose a PC specialty, the patient population and health promotion were considered important influences. Observing an immediate result in their patients was the most influential factor cited by students in the SS group. The variables that influenced students' career interests upon entry to medical school are presented in Table 4.

Table 2 Baseline characteristics and specialty groups $(n=436)$

\begin{tabular}{llll}
\hline Variable & Category & $n$ & $\%$ \\
\hline Sex & Male & 250 & 57 \\
Academic year & Female & 186 & 43 \\
& First & 131 & 30 \\
& Second & 134 & 31 \\
& Third & 118 & 27 \\
Specialty category & Final & 53 & 12 \\
& EM & 32 & 7 \\
& CL & 80 & 18 \\
& PC & 163 & 37 \\
& SS & 133 & 31 \\
& No preference & 28 & 6 \\
\hline
\end{tabular}

$E M$ emergency medicine, $C L$ controllable lifestyle, $P C$ primary care, $S S$ surgical specialty 
Table 3 Comparison of factors that influence the career interests of medical students

\begin{tabular}{|c|c|c|c|c|c|c|}
\hline \multirow[t]{2}{*}{ Factors } & \multicolumn{4}{|c|}{$\%$ of the students } & \multicolumn{2}{|c|}{ Results of ANOVA } \\
\hline & $\begin{array}{l}\mathrm{EM} \\
n=32\end{array}$ & $\begin{array}{l}\mathrm{CL} \\
n=80\end{array}$ & $\begin{array}{l}P C \\
n=163\end{array}$ & $\begin{array}{l}\text { SS } \\
n=133\end{array}$ & $F$ & $P$ value \\
\hline Medical lifestyle & 3.24 & 3.25 & 3.22 & 2.9 & 7.9 & $<0.001$ \\
\hline Social orientation & 3.14 & 3.39 & 3.48 & 3.12 & 8.81 & $<0.001$ \\
\hline Prestige & 2.8 & 3.05 & 2.93 & 3.13 & 2.27 & 0.08 \\
\hline Hospital orientation & 3.45 & 3.13 & 3.26 & 3.5 & 7.87 & $<0.001$ \\
\hline Role model & 3.14 & 2.68 & 2.94 & 3 & 2.94 & 0.033 \\
\hline Varied scope of practice & 3.19 & 3.28 & 3.25 & 3.24 & 0.12 & 0.948 \\
\hline
\end{tabular}

ANOVA analysis of variance, $E M$ emergency medicine, $C L$ controllable lifestyle, $P C$ primary care, $S S$ surgical specialty

Table 4 Variables that influence students' career interests at medical school

\begin{tabular}{|c|c|c|c|c|c|c|}
\hline \multirow[t]{2}{*}{ Factor } & \multicolumn{4}{|c|}{$\%$ of the students } & \multicolumn{2}{|c|}{ Results of ANOVA } \\
\hline & $\begin{array}{l}\mathrm{EM} \\
n=32\end{array}$ & $\begin{array}{l}\mathrm{CL} \\
n=80\end{array}$ & $\begin{array}{l}P C \\
n=163\end{array}$ & $\begin{array}{l}\text { SS } \\
n=133\end{array}$ & $\bar{F}$ & $P$ value \\
\hline Wide variety of patient problems & 3.97 & 3.15 & 3.27 & 3.35 & 3.96 & 0.008 \\
\hline Narrower variety of patient problems & 2.41 & 3.4 & 3.22 & 3.13 & 4.88 & 0.002 \\
\hline Good match to career & 2.75 & 2.55 & 2.55 & 2.38 & 0.86 & 0.464 \\
\hline Patient population is interesting & 4.13 & 3.9 & 3.94 & 3.95 & 0.36 & 0.783 \\
\hline Focus on in-hospital care & 3.41 & 3.45 & 3.63 & 3.8 & 2.4 & 0.067 \\
\hline Focus on patients in community & 2.87 & 3.4 & 3.61 & 3.12 & 6.53 & $<0.001$ \\
\hline Focus on urgent care & 4.25 & 2.63 & 2.9 & 3.74 & 26.5 & $<0.001$ \\
\hline Focus on non-urgent care & 2.47 & 3.56 & 3.39 & 3.03 & 10.2 & $<0.001$ \\
\hline Intervention results immediate & 4.22 & 2.99 & 3.32 & 3.98 & 18.84 & $<0.001$ \\
\hline High income potential & 3.13 & 3.55 & 3.27 & 3.72 & 5.35 & 0.001 \\
\hline Long-term patient relationship & 2.28 & 3.02 & 3.16 & 2.73 & 6.16 & $<0.001$ \\
\hline Status among colleagues & 2.97 & 3.07 & 3.17 & 3.19 & 0.44 & 0.726 \\
\hline Acceptable on-call schedule & 3.31 & 3.68 & 3.28 & 2.94 & 6.38 & $<0.001$ \\
\hline Do not like uncertainty & 2.81 & 3.09 & 3.04 & 3.04 & 0.44 & 0.728 \\
\hline Prefer medical to social problems & 3.53 & 3.04 & 3.26 & 3.44 & 2.08 & 0.102 \\
\hline Emulate physician & 3.03 & 2.64 & 3.09 & 3.28 & 3.56 & 0.014 \\
\hline Research interest & 3.03 & 3.59 & 3.26 & 3.28 & 1.82 & 0.143 \\
\hline Social commitment & 2.84 & 2.86 & 2.98 & 2.65 & 1.73 & 0.16 \\
\hline Stable/secure future & 2.31 & 2.54 & 2.36 & 2.48 & 0.56 & 0.644 \\
\hline Health promotion is important & 3.06 & 3.68 & 3.67 & 3.28 & 5.25 & 0.001 \\
\hline Acceptable hours of practice & 3.66 & 3.81 & 3.52 & 3.1 & 7.54 & $<0.001$ \\
\hline Flexibility inside of medicine & 3.69 & 3.62 & 3.64 & 3.26 & 4.06 & 0.007 \\
\hline Flexibility outside of medicine & 3.44 & 3.51 & 3.28 & 2.96 & 4.49 & 0.004 \\
\hline Keep options open & 3.53 & 3.19 & 3.59 & 3.17 & 4.76 & 0.003 \\
\hline Meaningful past experience & 3.5 & 2.71 & 2.96 & 3.11 & 3.21 & 0.023 \\
\hline Short postgraduate training & 2.75 & 2.26 & 2.68 & 2.24 & 3.9 & 0.009 \\
\hline Less intense residency program & 2.53 & 2.36 & 2.53 & 2.23 & 1.54 & 0.204 \\
\hline Experiences in health fields during medical school & 3.13 & 2.78 & 3.02 & 3.1 & 1.1 & 0.35 \\
\hline Experiences with role models during medical school & 3.31 & 2.74 & 3.07 & 3.14 & 2.53 & 0.057 \\
\hline Able to spend appropriate time with my family & 3.63 & 3.45 & 3.5 & 2.98 & 6.06 & $<0.001$ \\
\hline
\end{tabular}


Table 5 Comparison of students' demographic characteristics according to career choice

\begin{tabular}{lllll}
\hline Demographic characteristics & \multicolumn{4}{l}{ \% of students $(n=436)$} \\
\cline { 2 - 5 } & $\mathrm{EM}$ & $\mathrm{CL}$ & $\mathrm{PC}$ & $\mathrm{SS}$ \\
\hline Men compared with women & 56 & 44 & 51 & 69 \\
Men's preferences & 8 & 15 & 36 & 40 \\
Women's preferences & 8 & 25 & 44 & 23 \\
First-year students' preferences & 9 & 16 & 38 & 38 \\
Second-year students' preferences & 7 & 24 & 39 & 31 \\
Third-year students' preferences & 11 & 16 & 42 & 32 \\
Final-year students' preferences & 2 & 27 & 44 & 27
\end{tabular}

$E M$ emergency medicine, $C L$ controllable lifestyle, $P C$ primary care, $S S$ surgical specialty

We studied specialty choices in relation to the baseline characteristics of the respondents, as depicted in Table 5. Interestingly, male students were more numerous than females in the surgical specialties (69\%). Moreover, the sexes were more balanced in the EM group, with only slightly more male students (56\%). Females tended to choose CL and PC specialties more often than male students. Of great interest was the finding that students' preferences for surgical specialties decreased with years of study, whereas that for PC specialties increased. The rank order of factors influencing specialty choice for all four specialty groups was determined based on the mean for each factor, as shown in Table 6. Hospital orientation and medical lifestyle were the two most influential factors in the EM group. Conversely, the EM group was least influenced by prestige and social orientation. Varied scope of practice was among the top three influential factors in all groups. Meanwhile, prestige was among the bottom three factors affecting the EM, CL, and PC groups, but not the SS group.

\section{Discussion}

In recent years, the nature of medical specialization in Saudi Arabia has undergone many changes. Recently, a comprehensive plan to reform the economy and health, education, infrastructure, recreation, and tourism sectors of Saudi Arabia, termed Saudi Vision 2030, was unveiled. This plan will improve the integration and continuity of health service provision. Therefore, an increase in residency positions in PC and EM can be expected in the future [11]. Choosing a medical specialty is an important step that impacts the health-care workforce. It is an important predictor of the future supply of physicians in different specialties. According to Zeldow et al. [12] and DeWitt et al. [13], 45-70\% of medical students enter the specialty they preferred during medical school after they graduate. Thus, EM educators must be encouraged to understand the attitudes and priorities of medical students choosing a career in EM, the promotion of which may help to maximize the number of EM applicants. In this study, we aimed to investigate the influence of different factors on choosing a specialty.

Our findings revealed that only $7 \%$ of the medical students surveyed considered EM their first-choice specialty. This is consistent with other studies performed in the USA and Canada, which reported that EM was the first-choice specialty of 10 and $6.1 \%$ of students, respectively. We also found that $33.2 \%$ of the students considered EM a possible career and ranked it among their top three career choices.

Our study also provides insight into the factors that influence the career choices of medical students. Our data suggest that hospital orientation and medical lifestyle are the most influential factors when choosing EM as a future specialty. A focus on urgent care and observing immediate results of an intervention were the most frequently reported factors in the EM group, followed by the SS group. Conversely, a focus on non-urgent care was the most frequently cited factor in the CL and PC groups. In addition, we found that students who were interested in EM were more concerned about the medical lifestyle provided by their specialty than students who chose a CL specialty. According to Dorsey et al. [2], because of the similarities between EM and CL specialties, EM can be considered a CL specialty. The term CL was first introduced in 1989 by Schwartz et al. [3] and defined as the ability to have control over working hours.

However, in comparison to other CL specialties, the lifestyle provided by EM as a medical specialty differs. The flexibility of working hours is an advantage of EM. In our study, flexibility of working hours as an influence

Table 6 Rank order of factors by specialty group

\begin{tabular}{llll}
\hline Rank & EM & CL & PC \\
\hline 1 & Hospital orientation & Social orientation & Social orientation \\
2 & Medical lifestyle & Varied scope of practice & Hospital orientation \\
3 & Varied scope of practice & Medical lifestyle & Varied scope of practice \\
4 & Role model & Hospital orientation & Medical lifestyle \\
6 & Social orientation & Prestige & Role model scope of practice \\
\hline
\end{tabular}

EM emergency medicine, $C L$ controllable lifestyle, $P C$ primary care, $S S$ surgical specialty 
on career choice was most frequently cited in the EM group compared with the other groups. The EM group also reported the strong influence of the intensity and length of the training program. The lifestyle provided by EM may explain the high career satisfaction reported by EM physicians. In a longitudinal study of career satisfaction associated with EM, $65.2 \%$ of EM physicians reported high career satisfaction [14]. However, of all the specialties, EM physicians tend to have the highest rates of burnout. A recent study found that at least half of EM physicians suffered burnout as early as the second year of training in an EM residency program [15].

The effect of exposure to a role model on medical students can be summarized in three main outcomes: shaping of career aspirations, development of a professional identity, and behavior [15]. We found that the influence of mentors and role models on the choice of medical specialty was low in all four groups. It is difficult to compare our studies to studies conducted in the USA because of differences in the curriculum and teaching methods. However, exposure to a role model was ranked as the second most influential factor on medical students' choice of a career in EM and the first most influential factor for their choice of other specialties in US medical colleges [4]. Moreover, salary expectation was considered more of influence for American medical students who are interested in EM [4]. These differences between students could be explained by the cultural and social status in each country, which could affect the different abovementioned domains. A lack of formal career counseling for our students may be the reason. A trial of a mentoring program was established in the northeastern USA in an attempt to increase the number of students interested in PC. First-year medical students who were interested in PC were paired with PC mentors. Those students were successfully matched to PC programs at a rate of $87.5 \%$. They appreciated the relationship with their mentors, which positively influenced their interest in a PC career [16]. In our study, the effect of mentors and role models was ranked as the fourth most influential factor for students interested in a career in EM. However, of the students surveyed, the EM group reported the greatest influence of exposure to role models in their desired health field during medical school. This result may be explained by the excellent EM Department at the $\mathrm{Na}$ tional Guard Hospital where our students receive a compulsory 4-week training course after their first year at medical college.

EM educators are in short supply compared with more established specialties such as surgery and internal medicine [17]. Establishing meaningful mentoring relationships between EM physicians and students may help to provide future mentors, because some of these students will develop into future leaders and mentors in the field of EM [17].
Perceived prestige and financial reward were most commonly associated with a surgical career choice. The SS group reported the highest influence of salary and status among colleagues. In contrast to the SS group, prestige had the least influence on the career choices of the EM Group.

\section{Conclusions}

The trends in specialty choice should be appraised to meet the future needs of the Kingdom of Saudi Arabia. We found that students primarily interested in EM have different values and career expectations to those interested in careers in other specialties. We showed that hospital orientation and medical lifestyle are influential factors on the formulation of their specialty preferences. These findings may help program directors and chairs in the specialty of EM to attract more students. Our findings may also be helpful to medical students and careers counselors in the specialty selection process. We cannot make a prediction about the EM health workforce in Saudi Arabia based on our results. However, we can conclude that students who are interested in EM are concerned about the hospital orientation and lifestyle that the training program in EM provides.

\section{Abbreviations \\ CL: Controllable lifestyle; EM: Emergency Medicine; KSAU-HS: King Saud bin Abdulaziz University for Health Sciences; PC: Primary Care; SBEM: Saudi Board} of Emergency Medicine; SS: Surgical Subspecialty; US: United States

\section{Acknowledgements}

The authors thank the publication office at King Abdullah International Medical Research Center for their support in reviewing and editing the manuscript.

\section{Funding}

None.

\section{Availability of data and materials} Not applicable.

\begin{abstract}
Authors' contributions
$\mathrm{HK}, \mathrm{FH}$, and KS designed the study, collected the data, and wrote the manuscript. NJ designs the study, supervised the conductance of the survey and data collection, and reviewed the manuscript. FH performed the statistical analysis. All authors interpreted the survey results, participated in the related discussions, and read and approved the final version of the manuscript.
\end{abstract}

\section{Ethics approval and consent to participate}

The study was approved by the institutional review board of the King Abdullah International Medical Research Centre. Written informed consent forms were distributed to the students. Only those who agreed to participate in the study were enrolled. Incomplete questionnaires were not included in the study.

Consent for publication

Not applicable.

Competing interests

The authors declare that they have no competing interests. 


\section{Publisher's Note}

Springer Nature remains neutral with regard to jurisdictional claims in published maps and institutional affiliations.

\section{Author details}

${ }^{1}$ College of Medicine, King Saud bin Abdulaziz University for Health Sciences, Riyadh, Saudi Arabia. ${ }^{2}$ Department of Emergency Medicine, Ministry of National guard health affairs, P.O Box 86871, Riyadh 11632, Saudi Arabia.

Received: 25 September 2017 Accepted: 15 February 2018

Published online: 07 March 2018

\section{References}

1. Scott IM, Abu-Laban RB, Gowans MC, Wright BJ, Brenneis FR. Emergency medicine as a career choice: a descriptive study of Canadian medical students. CJEM. 2009;11:196-206.

2. Dorsey ER, Jarjoura D, Rutecki GW. Influence of controllable lifestyle on recent trends in specialty choice by US medical students. JAMA. 2003;290:1173.

3. Schwartz RW, Jarecky RK, Strodel WE, Haley JV, Young B, Griffen WO. Controllable lifestyle: a new factor in career choice by medical students. Acad Med. 1989;64:606-9.

4. Boyd JS, Clyne B, Reinert SE, Zink BJ. Emergency medicine career choice: a profile of factors and influences from the Association of American Medical Colleges (AAMC) graduation questionnaires. Acad Emerg Med. 2009;16:544-9.

5. Wright B, Scott I, Woloschuk W, Brenneis F, Bradley J. Career choice of new medical students at three Canadian universities: family medicine versus specialty medicine. CMAJ. 2004;170:1920-4.

6. Correia Lima de Souza L, Mendonça VRR, Garcia GBC, Brandão EC, BarralNetto M. Medical specialty choice and related factors of Brazilian medical students and recent doctors. PLoS One. 2015;10:e0133585.

7. Saigal P, Takemura Y, Nishiue T, Fetters MD. Factors considered by medical students when formulating their specialty preferences in Japan: findings from a qualitative study. BMC Med Educ. 2007;7:31.

8. Al-Fouzan R, Al-Ajlan S, Marwan Y, Al-Saleh M. Factors affecting future specialty choice among medical students in Kuwait. Med Educ Online. 2012;17:1-7

9. Kazzi AA, Langdorf Ml, Ghadishah D, Handly N. Motivations for a career in emergency medicine: a profile of the 1996 US applicant pool. CJEM. 2001;3:99-104.

10. Alghamdi K, Alburaih A, Wagner MJ. A comparison between emergency medicine residency training programs in the United States and Saudi Arabia from the residents' perception. Emerg Med Int. 2014;2014:362624.

11. Julie Bassi. Vision 2030 and the opportunities it represents in healthcare in Saudi Arabia - Al Tamimi \&amp; Company. Dec-Jan. 2017. http://www. tamimi.com/en/magazine/law-update/section-14/dec-jan-2017/vision-2030and-the-opportunities-it-represents-in-healthcare-in-saudi-arabia.html (accessed 14 Sep 2017).

12. Zeldow PB, Preston RC, Daugherty SR. The decision to enter a medica specialty: timing and stability. Med Educ. 1992;26:327-32.

13. DeWitt DE, Curtis JR, Burke W. What influences career choices among graduates of a primary care training program? J Gen Intern Med. 1998;13:257-61.

14. Cydulka RK, Korte R. Career satisfaction in emergency medicine: the ABEM Longitudinal Study of Emergency Physicians. Ann Emerg Med. 2008:51:714-722.e1.

15. Lu D, Dresden S, McCloskey C, Branzetti J, Gisondi M. Impact of burnout on self-reported patient care among emergency physicians. West J Emerg Med. 2015;16:996-1001

16. Indyk D, Deen D, Fornari A, Santos MT, Lu W-H, Rucker L. The influence of longitudinal mentoring on medical student selection of primary care residencies. BMC Med Educ. 2011:11:27.

17. Garmel GM. Mentoring medical students in academic emergency medicine. Acad Emerg Med. 2004;11:1351-7.

\section{Submit your manuscript to a SpringerOpen ${ }^{\circ}$ journal and benefit from:}

- Convenient online submission

- Rigorous peer review

Open access: articles freely available online

- High visibility within the field

Retaining the copyright to your article

Submit your next manuscript at $>$ springeropen.com 